\title{
IFN- $\gamma$ stimulates osteoclast formation and bone loss in vivo via antigen-driven T cell activation
}

\author{
Yuhao Gao, ${ }^{1}$ Francesco Grassi, ${ }^{1}$ Michaela Robbie Ryan,, ${ }^{1}$ Masakazu Terauchi, ${ }^{1}$ Karen Page, ${ }^{1}$ \\ Xiaoying Yang, ${ }^{1}$ M. Neale Weitzmann, ${ }^{1}$ and Roberto Pacifici ${ }^{1,2}$ \\ ${ }^{1}$ Division of Endocrinology, Metabolism and Lipids, Department of Medicine, and ${ }^{2}$ Immunology and Molecular Pathogenesis Program, \\ Emory University, Atlanta, Georgia, USA.
}

\begin{abstract}
T cell-produced cytokines play a pivotal role in the bone loss caused by inflammation, infection, and estrogen deficiency. IFN- $\gamma$ is a major product of activated $\mathrm{T}$ helper cells that can function as a pro- or antiresorptive cytokine, but the reason why IFN- $\gamma$ has variable effects in bone is unknown. Here we show that IFN- $\gamma$ blunts osteoclast formation through direct targeting of osteoclast precursors but indirectly stimulates osteoclast formation and promotes bone resorption by stimulating antigen-dependent $T$ cell activation and $T$ cell secretion of the osteoclastogenic factors RANKL and TNF- $\alpha$. Analysis of the in vivo effects of IFN- $\gamma$ in 3 mouse models of bone loss - ovariectomy, LPS injection, and inflammation via silencing of TGF- $\beta$ signaling in T cells - reveals that the net effect of IFN- $\gamma$ in these conditions is that of stimulating bone resorption and bone loss. In summary, IFN- $\gamma$ has both direct anti-osteoclastogenic and indirect pro-osteoclastogenic properties in vivo. Under conditions of estrogen deficiency, infection, and inflammation, the net balance of these 2 opposing forces is biased toward bone resorption. Inhibition of IFN- $\gamma$ signaling may thus represent a novel strategy to simultaneously reduce inflammation and bone loss in common forms of osteoporosis.
\end{abstract}

\section{Introduction}

Physiological osteoclast renewal is regulated by the key osteoclastogenic cytokines M-CSF and receptor activator of NF- $\mathrm{B}$ ligand (RANKL). However, under pathological conditions, such as those occurring during inflammation, infection, and estrogen deficiency, bone resorption is significantly stimulated due to dysregulated production of additional pro- and anti-osteoclastogenic factors, including IFN- $\gamma$, a central mediator of adaptive immunity. Estrogen deficiency, infection by LPS-producing bacteria such as occurs in periodontitis, and inflammatory diseases like RA are all characterized by a state of immune activation, leading to elevated production of IFN- $\gamma$ by Th1 cells (1-5).

Substantial evidence demonstrates that IFN- $\gamma$ strongly suppresses osteoclastogenesis in vitro $(6,7)$. However, other studies have shown that IFN- $\gamma$ enhances osteoclast generation in cultures of peripheral blood from osteopetrotic patients, in part by normalizing superoxide production (8). Additional studies revealed that preexposure of osteoclast precursors to RANKL renders them resistant to the inhibitory effects of IFN- $\gamma$ by inducing terminal differentiation (9). Furthermore, IFN- $\gamma$-producing human Th1 cells, but not IFN- $\gamma$-negative T cells, were found to directly induce the differentiation of human macrophages into osteoclasts via expression of RANKL (10).

The effects of IFN- $\gamma$ in vivo are equally controversial. Silencing of IFN- $\gamma$ receptor (IFN- $\gamma \mathrm{R}$ ) signaling led to a more rapid onset of

Nonstandard abbreviations used: BMD, bone mineral density; BMM, BM macrophage; BV/TV, trabecular bone volume; CIITA, class II transactivator; CM, conditioned medium; CTX, C-terminal telopeptide; DXA, dual x-ray absorptiometry; IFN- $\gamma \mathrm{R}$, IFN- $\gamma$ receptor; ovx, ovariectomy, ovariectomized; RANKL, receptor activator of NF-кB ligand; rIFN- $\gamma$, recombinant IFN- $\gamma$; TRAF6, TNF receptor-associated factor 6 ; TRAP, tartrate-resistant acid phosphatase.

Conflict of interest: The authors have declared that no conflict of interest exists. Citation for this article: J. Clin. Invest. 117:122-132 (2007). doi:10.1172/JCI30074. collagen-induced arthritis and bone resorption (11). Furthermore, IFN- $\gamma$ was found to decrease serum calcium and osteoclastic bone resorption in vivo in nude mice $(12,13)$, suggesting that IFN- $\gamma$ is a bone-sparing cytokine in vivo. In contrast, observations in humans and rodents suggest that IFN- $\gamma$ promotes bone resorption and causes bone loss in a variety of pathological conditions. For example, IFN- $\gamma$ has been reported to be efficacious in the treatment of osteopetrosis through restoration of osteoclast formation and bone resorption, in both humans (14) and rodents (15). Addition of recombinant IFN- $\gamma(\mathrm{rIFN}-\gamma)$ rescues the defect in osteoclastogenesis in peripheral white blood cells from malignant osteopetrosis patients in vitro (8). Systemic administration of rIFN- $\gamma$ causes loss of bone volume in rats $(16,17)$. Moreover, mice lacking IFN- $\gamma$ production are protected against infection-induced alveolar bone loss (18), and IFN- $\gamma$ receptor $^{-/-}\left(I F N-\gamma R^{-/-}\right)$mice fail to undergo ovariectomy-induced (ovx-induced) bone loss (2). Furthermore, IFN- $\gamma$ production correlates positively with tissue destruction in erosive tuberculoid leprosy, and bone resorption in psoriatic arthritis $(19,20)$ increases in parallel with bacterial LPS-induced bone resorption in mice (21) and positively modulates actinobacillus actinomycetemcomitans-specific $\mathrm{RANKL}^{+} \mathrm{CD}^{+}{ }^{+}$Th cell-mediated alveolar bone destruction in vivo (22). Further support for the hypothesis that IFN- $\gamma$ does not inhibit bone resorption in vivo was provided by the outcome of randomized controlled trials which have shown that IFN- $\gamma$ does not prevent bone loss in patients with RA $(23,24)$ or the bone-wasting effect of cyclosporin A (16).

IFN- $\gamma$ has been shown to directly block osteoclast formation by inducing the rapid degradation of the RANK adapter protein TNF receptor-associated factor 6 (TRAF6), resulting in strong inhibition of the RANKL-induced activation of NF-KB and c-Jun $\mathrm{N}$-terminal kinase (25). IFN- $\gamma$ also downregulates the RANKL signaling pathway by antagonizing RANKL-stimulated cathepsin $\mathrm{K}$ $(7,26,27)$ and by upregulating cathepsin S and cathepsin L gene 
expression in preosteoclastic cells (26). Furthermore, IFN- $\gamma$ induces superoxide production in osteoclasts, inducing apoptosis of osteoclast progenitors and suppressing osteoclast activity $(28,29)$. However, IFN- $\gamma$ is the physiologic inducer of MHC class II expression and thus of antigen presentation (30-32). As a result, IFN- $\gamma$ leads to $\mathrm{T}$ cell activation and $\mathrm{T}$ cell secretion of the osteoclastogenic factors RANKL and TNF- $\alpha$ (2). Together, these data suggest that IFN- $\gamma$ inhibits osteoclast formation through direct targeting of maturing osteoclasts, while it promotes osteoclastogenesis indirectly, by stimulating $\mathrm{T}$ cell activation.

In this study, we investigated the hypothesis that the net effect of IFN- $\gamma$ on bone resorption in vivo represents the balance of its direct and indirect activities. We report that IFN- $\gamma$ promotes osteoclast formation through stimulation of antigen-dependent $\mathrm{T}$ cell activation and show that under conditions of estrogen deficiency, infection, and direct $T$ cell activation by suppression of TGF- $\beta$ signaling, the net effect of IFN- $\gamma$ is that of inducing bone resorption and bone loss.

\section{Results}

IFN- $\gamma$ blocks osteoclastogenesis via direct targeting of maturing osteoclast precursors but stimulates osteoclast formation through upregulation of antigen presentation. To investigate the direct effects of IFN- $\gamma$ on osteoclast formation, macrophages were purified by positive immunomagnetic selection from either the BM or the spleen of intact WT mice and cultured with optimal amounts of RANKL and M-CSF and increasing doses of rIFN- $\gamma$. RANKL equally stimulated the differentiation of BM and splenic macrophages into osteoclasts, and IFN- $\gamma$ dose-dependently inhibited osteoclastogenesis, with significant suppression occurring at $1 \mathrm{ng} / \mathrm{ml}$ and complete suppression at $100 \mathrm{ng} / \mathrm{ml}$ of rIFN- $\gamma$ (Figure 1A). These findings confirm earlier reports that IFN- $\gamma$ has direct anti-osteoclastogenic effects on RANKL-induced osteoclastogenesis in vitro $(7,25-27)$.

Since IFN- $\gamma$ is a potent inducer of MHC class II expression and antigen presentation in macrophages, IFN- $\gamma$ may induce $\mathrm{T}$ cell secretion of osteoclastogenic factors by promoting antigen-dependent $\mathrm{T}$ cell activation. To test this hypothesis, BM macrophages (BMMs) were used as APCs (herein designated as APC-BMMs) and were purified from WT mice and pretreated with rIFN- $\gamma$ for 72 hours to upregulate MHC class II expression. After removal of rIFN- $\gamma$ by washing, these cells were cocultured for 72 hours with the avian antigen OVA and T cells from OT-II mice, a strain with $\mathrm{T}$ cells that harbor a transgenic $\mathrm{T}$ cell receptor responsive exclusively to OVA. In this model, OVA-derived peptides presented by APCs to $T$ cells induce $T$ cell activation and $T$ cell cytokine secretion. Measurements of cytokine levels in the conditioned medium (CM) revealed that pretreatment of APC-BMMs with rIFN- $\gamma$ led to a significant increase in TNF- $\alpha$, RANKL, and IFN- $\gamma$ production, as compared with pretreatment of APC-BMMs with vehicle (Figure 1B). To demonstrate that $T$ cells were a major source of the secreted cytokines, $\mathrm{T}$ cells were purified by positive immunomagnetic selection at the end of the coculture and analyzed by real-time RT-PCR. The data show that pretreatment of APC-BMMs with rIFN- $\gamma$ significantly increased the T cell expression of TNF- $\alpha$, IFN- $\gamma$, and RANKL mRNA (Figure 1C).

In order to investigate the indirect pro-osteoclastogenic effect of IFN- $\gamma$ in the absence of its direct anti-osteoclastogenic activity, we utilized early osteoclast precursors (macrophages) that were derived from $I F N-\gamma R^{-/-}$mice. The preosteoclasts and osteoclasts formed from these cells are consequently insensitive to IFN- $\gamma$ and thus resistant to the direct anti-osteoclastogenic effect of IFN- $\gamma$. Osteoclastogenesis was initiated by addition to osteoclast precursors from IFN- $\gamma R^{-1-}$ mice of CM derived from T cells that had been activated in vitro by WT APCs, in the presence or absence of IFN- $\gamma$. Under these conditions, osteoclast formation reflects the capacity of IFN- $\gamma$ to stimulate antigen-induced cytokine production by $\mathrm{T}$ cells. We found that the number of osteoclasts produced in response to CM from $\mathrm{T}$ cells that had been activated in vitro by WT APCs, in the presence of IFN- $\gamma$, was 2 -fold higher than that induced by $\mathrm{CM}$ generated in the absence of IFN- $\gamma$. When the same experiment was repeated using osteoclast precursors from WT mice, rIFN- $\gamma$-pretreated APCs and unstimulated APCs induced equal osteoclast formation (Figure 1D). These findings suggest that under these conditions, the indirect pro-osteoclastogenic effect of IFN- $\gamma$ is neutralized by the direct anti-osteoclastogenic activity of the IFN- $\gamma$ secreted by activated T cells. Together, these data demonstrate that IFN- $\gamma$ represses osteoclastogenesis by directly repressing the differentiation of macrophages into osteoclasts but indirectly stimulates osteoclast formation through stimulation of antigen presentation.

We have previously reported that ovx increases MHC class II expression in macrophages and monocyte APC activity (2). We took advantage of this phenomenon to further investigate the indirect effects of IFN- $\gamma$ on osteoclast formation. Thus, APC-BMMs from WT sham-operated and ovx mice were cocultured with OVA and $\mathrm{T}$ cells from OT-II mice. T cell CM was then collected 72 hours after culture, added to a new batch of osteoclast precursors from intact WT mice, and cultured for 7 days with M-CSF and RANKL in the presence or absence of neutralizing anti-IFN- $\gamma \mathrm{Ab}(\mathrm{IFN}-\gamma \mathrm{Ab})$. Osteoclast formation in the samples treated with IFN- $\gamma$ Ab reflected the impact of stimulated IFN- $\gamma$-driven antigen presentation by macrophages without the direct inhibitory effect of the cytokine. Under these conditions, osteoclast formation was approximately 3-fold higher in samples containing APC-BMM CM from ovx mice compared with those with APC-BMM CM from sham-operated mice (Figure 1E). In the absence of IFN- $\gamma \mathrm{Ab}$, osteoclast formation was only 2 -fold higher in samples with APC-BMMs from ovx mice than those with APC-BMMs from sham-operated mice, reflecting the direct inhibitory effect of IFN- $\gamma$. These data confirm that IFN- $\gamma$ directly suppresses osteoclast formation. However, under conditions of estrogen deficiency, the overall balance between the stimulatory effect of antigen presentation on $T$ cell activation and the direct suppressive effect of IFN- $\gamma$ is a net increase in osteoclast formation.

To further investigate the mechanism by which IFN- $\gamma$ regulates osteoclast formation, $\mathrm{T}$ cells were activated in vitro with PMA and ionomycin and cultured for 3 days. T cell CM was added to BMMs along with optimal amounts of RANKL and M-CSF, and the mixture cultured for an additional 3-day period with and without Abs against IFN- $\gamma$, TNF- $\alpha$, and RANKL to induce the differentiation of $\mathrm{BMMs}$ into $\mathrm{TRAP}^{+}$mononuclear osteoclast precursors in the absence of the direct effects of the neutralized cytokines. At the end of the culture period, the proliferation of the nascent osteoclasts was measured by thymidine incorporation; their rate of apoptosis by intracellular caspase-3 activity; and their expression of TRAP mRNA, a marker of osteoclast differentiation, by real-time PCR.

These experiments revealed that in conditions in which the direct effect of IFN- $\gamma$ is neutralized, cytokines released by activated $\mathrm{T}$ cells increase both the proliferation (Figure $1 \mathrm{~F}$ ) and the survival of osteoclast precursors (Figure $1 \mathrm{G}$ ), while they have no effect on the rate of their differentiation (data not shown). Acti- 

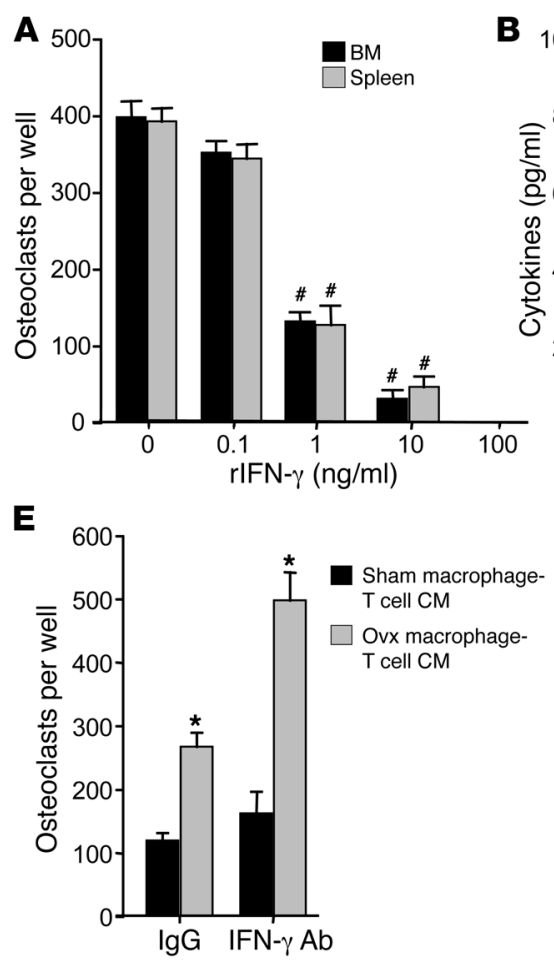

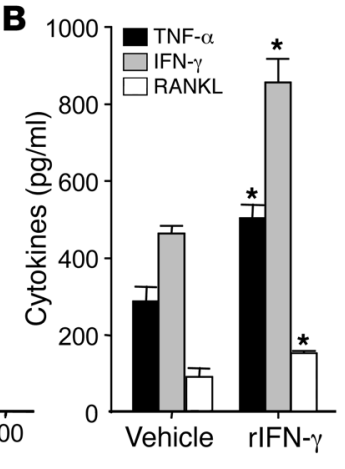

$\mathbf{F}$

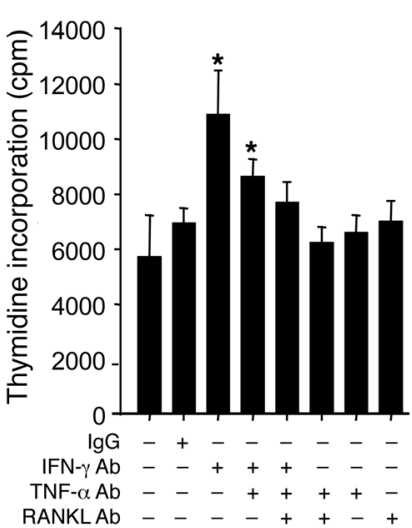

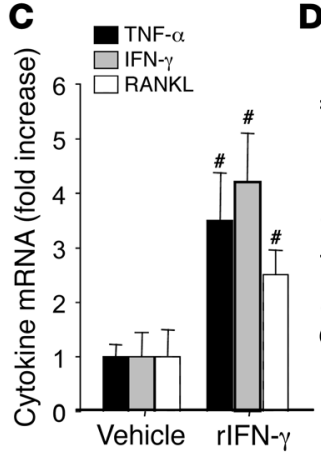

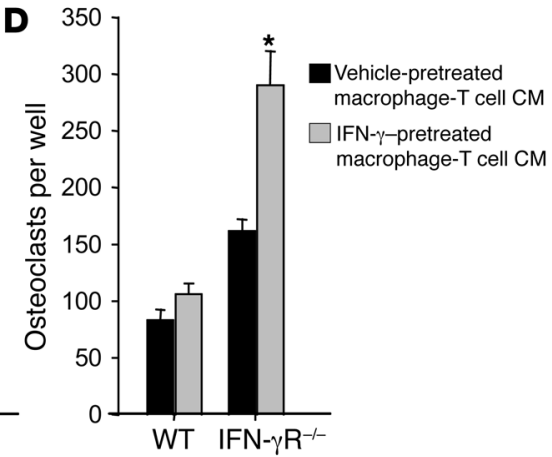

G

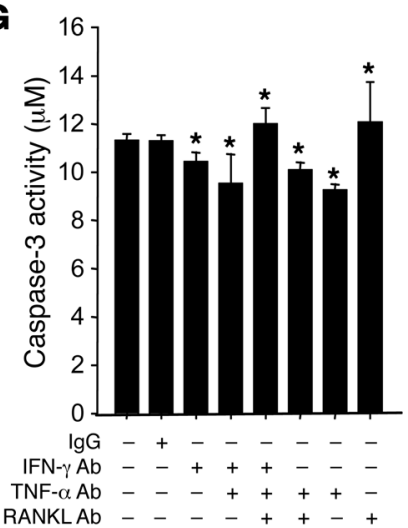

Figure 1

IFN- $\gamma$ directly suppresses and indirectly stimulates osteoclastogenesis in vitro. (A) rIFN- $\gamma$ suppresses osteoclastogenesis induced by RANKL $(50 \mathrm{ng} / \mathrm{ml})$ and M-CSF $(10 \mathrm{ng} / \mathrm{ml})$ in macrophages purified from BM and spleen. ${ }^{\#} P<0.01$ compared with vehicle-treated controls. (B) Cytokine levels in CM derived from cocultures of IFN- $\gamma$-pretreated WT macrophages and OT-II T cells were measured using ELISA. ${ }^{*} P<0.05$ compared with vehicle-treated controls. (C) The expression of T cell cytokine mRNA was measured by real-time RT-PCR in T cells cocultured with rlFN- $\gamma-$ pretreated macrophages. ${ }^{\#} P<0.01$ compared with vehicle-pretreated controls. (D) The ability of CM from cocultures of rIFN- $\gamma-$ pretreated macrophages and OT-II T cells to enhance M-CSF- and RANKL-stimulated osteoclastogenesis was examined in macrophages from WT and IFN- $\gamma R^{-1-}$ mice. ${ }^{*} P<0.05$ compared with vehicle-treated controls. (E) The ability of CM from coculture of macrophages from sham-operated or ovx WT mice and OT-II T cells to induce osteoclastogenesis was examined in macrophages from WT mice in the presence of M-CSF and RANKL with or without neutralizing IFN- $\gamma \mathrm{Ab}(10 \mu \mathrm{g} / \mathrm{ml})$. ${ }^{*} P<0.05$ compared with vehicle-treated controls. The proliferation $(\mathbf{F})$ and rate of apoptosis (G) of maturing osteoclasts were determined by [ $\left.{ }^{3} \mathrm{H}\right]$ thymidine incorporation and intracellular caspase-3 activity in 3-day cultures of RANKL-and M-CSF-stimulated BMMs cultured in the presence of activated T cell CM and Abs directed against IFN- $\gamma$, TNF, and RANKL. ${ }^{*} P<0.05$ compared with irrelevant IgG-treated controls. All data are expressed as mean \pm SD.

vated $\mathrm{T}$ cells stimulate the proliferation of osteoclast precursors by secreting TNF and RANK, as the stimulatory effect of T cell $\mathrm{CM}$ was abolished by the neutralization of these cytokines. The capacity of IFN- $\gamma$-neutralized T cell CM to blunt the apoptosis of maturing osteoclasts was further enhanced by anti-TNF- $\alpha$ Ab and reversed by neutralization of RANKL, demonstrating that IFN- $\gamma$ and TNF- $\alpha$ increase preosteoclast apoptosis while RANKL suppresses it. Taken together, the data demonstrate that activated $\mathrm{T}$ cells stimulate the proliferation and survival of maturing osteoclasts through TNF and RANKL, while inhibiting these processes through the direct activity of IFN- $\gamma$.

IFN- $\gamma$ causes bone loss in T cell-replete but not T cell-deficient mice. Having established the direct and indirect effects of IFN- $\gamma$ in vitro, we verified our findings in vivo by examining the effects of treatment with rIFN- $\gamma$ in nude mice, a strain in which the indirect effects of IFN- $\gamma$ are abrogated by the lack of T cells. Thus, 16-weekold WT nude mice and nude mice subjected to adoptive transfer of WT T cells 2 weeks earlier were injected i.p. twice a week for 3 weeks with rIFN- $\gamma\left(10^{6} \mathrm{IU} / \mathrm{kg}\right)$. Bone mineral density (BMD) was measured by dual x-ray absorptiometry (DXA), a technique that provided a combined assessment of cortical and trabecular bone, at baseline and at 3 weeks after initial rIFN- $\gamma$ injection. rIFN- $\gamma$ treatment led to a significant decrease in spine BMD in WT and T cell-replete nude mice, but not in T cell-deficient nude mice (Figure $2 \mathrm{~A}$ ). Consistent with the BMD data, treatment with IIFN- $\gamma$ also caused a significant increase in the serum level of C-terminal telopeptides (CTXs), a marker of bone resorption, in WT mice and $\mathrm{T}$ cell-reconstituted nude mice, but not in $\mathrm{T}$ cell-deficient nude mice (Figure 2B). The serum level of osteocalcin, a marker of bone formation, did not change in response to in vivo rIFN- $\gamma$ treatment in any of the groups of mice, indicating that the changes in BMD induced by IFN- $\gamma$ were not due to blunted bone formation (Figure 2C). T cell production of TNF- $\alpha$, RANKL, and IFN- $\gamma$ was increased by rIFN- $\gamma$ in the T cell-replete groups (Figures 2, $\mathrm{D}-\mathrm{F})$. Due to the absence of T cells in nude mice, cytokine levels fell below detection in this group. These findings demonstrate that $\mathrm{T}$ cells are critical to the mechanism by which IFN- $\gamma$ stimulates bone resorption in vivo. 

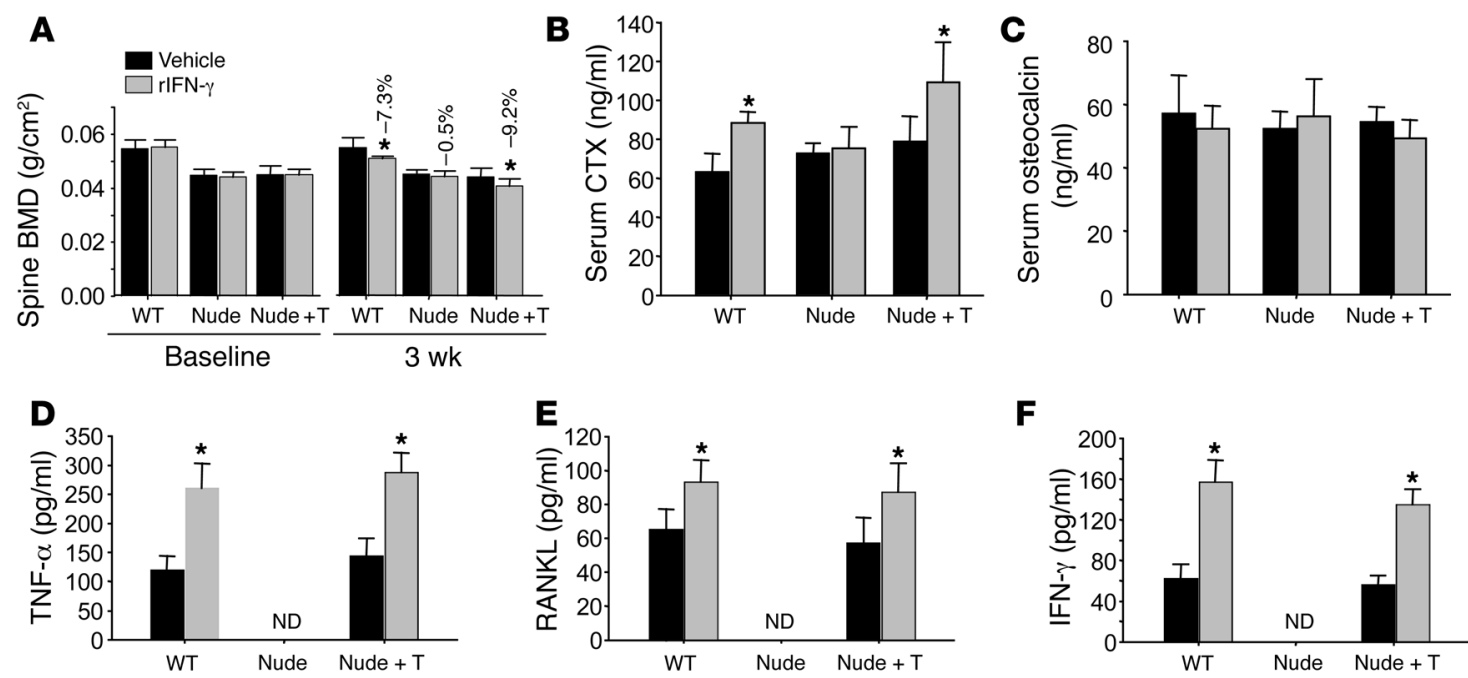

Figure 2

Systemic administration of rIFN- $\gamma$ stimulates bone resorption in WT mice and nude mice reconstituted with WT T cells (Nude $+\mathrm{T}$ ), but not in T cell-deficient nude mice. rIFN- $\gamma\left(1 \times 10^{6} \mathrm{IU} / \mathrm{kg}\right.$ body weight $)$ was injected subcutaneously twice a week into 16-week-old WT mice, T cell-deficient nude mice, and nude mice reconstituted with WT T cells, and spine BMD (A); serum CTX (B) and serum osteocalcin levels (C); and T cell production of TNF (D), RANKL (E), and IFN- $\gamma(\mathbf{F})$ were measured 3 weeks after initial IFN- $\gamma$ injection. The percentages in $\mathbf{A}$ represent the change compared with baseline. All data are expressed as mean \pm SD. ${ }^{*} P<0.05$ compared with vehicle-treated controls. ND, not detectable.

Effects of IFN- $\gamma$ in ovx mice. Since the pattern of T cell activation varies in different pathological conditions, we next compared the effects of IFN- $\gamma$ on bone homeostasis in estrogen deficiency and LPS-induced inflammation, 2 conditions that cause bone loss through $\mathrm{T}$ cell-dependent mechanisms $(3,4,33,34)$. We also examined an experimental model of autoimmune disease induced by specifically ablating TGF- $\beta$ signaling in T cells (35).

To investigate the role of IFN- $\gamma$ in the bone loss induced by estrogen deficiency, WT and $I F N-\gamma^{-/-}$mice were sham operated or subjected to ovx at the age of 16 weeks and sacrificed 4 weeks later. In vivo measurements of spine BMD at baseline and 4 weeks after surgery by DXA revealed that ovx caused a significant bone loss in WT but not in $I F N-\gamma^{-/-}$mice (Figure 3A), suggesting that $I F N-\gamma^{-/}$mice are protected against the overall loss of cortical and trabecular bone induced by ovx. $\mu \mathrm{CT}$ analysis of femurs obtained at sacrifice revealed that ovx caused a loss of trabecular bone volume (BV/TV) in both WT mice and $I F N-\gamma^{-/-}$mice (Figure 3B). However, the difference between sham-operated and ovx mice

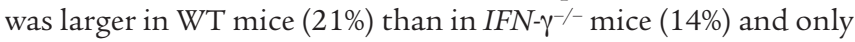
reached statistical significance in WT mice. Together, these findings indicate that $I F N-\gamma^{-/-}$mice are partially protected against the loss of trabecular bone induced by ovx. At 4 weeks from surgery, the levels of serum CTX and osteocalcin were higher in WT ovx mice than in WT sham-operated controls (Figure 3, C and D). In contrast, $I F N-\gamma^{-/-}$sham-operated and ovx mice had similar levels of both CTX and osteocalcin. Flow cytometric analysis revealed that ovx increases the percentage of $\mathrm{CD} 4^{+} \mathrm{T}$ cells expressing the early activation marker CD69 in WT but failed to stimulated T cell activation in $I F N-\gamma^{-/}$mice (Figure $3 \mathrm{E}$ ). This data are consistent with previous reports demonstrating that ovx leads to significant activation and expansion of TNF-producing T cell populations $(34,36)$ and that IFN- $\gamma$ plays a causal role in the bone loss induced by estrogen deficiency (2).

Effects of IFN- $\gamma$ in LPS-induced bone loss. To investigate the contribution of IFN- $\gamma$ to LPS-induced bone resorption in vivo, WT and
IFN- $\gamma^{-/-}$mice of 10 weeks of age were injected subcutaneously with LPS ( $25 \mathrm{mg} / \mathrm{kg}$ once a week for 3 weeks) and BMD measured at baseline and weekly thereafter. LPS injection led to a significant reduction in spine BMD in both WT and $I F N-\gamma^{-/-}$mice (Figure 4A), although in $I F N-\gamma^{-/}$mice, bone loss plateaued at 2 weeks, while in WT mice there was a progressive bone loss for the 3 weeks of followup. As a result, the bone loss at 3 weeks was significantly greater in WT ( 16.5\%) than in $I F N-\gamma^{-/-}$mice ( 10.5\%). $\mu \mathrm{CT}$ analysis of femur trabecular bone in samples harvested at 3 weeks showed (Figure 4B) that LPS caused a decrease in BV/TV in both WT $(\sim 30 \%)$ and IFN $-\gamma^{-/-}$mice $(\sim 23 \%)$. Although there was a trend toward less bone loss in $I F N-\gamma^{-/-}$mice, the difference between the 2 groups was not significant. In contrast to the effects on bone volume, LPS caused a larger increase in CTX levels in WT than in IFN- $\gamma^{-/-}$mice (Figure 4C). However, in all groups of mice, LPS had no significant effects on serum osteocalcin (Figure 4D).

As expected $I F N-\gamma^{-/-}$mice had lower basal APC activity and a negligible response to LPS. In contrast, WT mice had a higher APC activity at baseline, and LPS caused a further 2-fold increase in APC activity (Figure 4E). LPS treatment also resulted in an approximately 3 -fold and approximately 1.5 -fold increase in the percentage of activated $\left(\mathrm{CD} 69^{+}\right) \mathrm{CD}^{+} \mathrm{T}$ cells in WT mice and $\mathrm{IFN}-\gamma^{-/-}$mice, respectively (Figure $4 \mathrm{~F}$ ). Taken together, these data suggest that LPS induces bone loss primarily via IFN- $\gamma$-independent mechanisms, although an IFN- $\gamma$-dependent mechanism plays a contributory role. The IFN- $\gamma$-dependent bone loss results from LPS stimulation of antigen presentation and the resulting $\mathrm{T}$ cell activation.

Silencing IFN- $\gamma$ production reduces the bone loss induced by the disruption of TGF- $\beta$ signaling in T cells. To further investigate the contribution of the indirect stimulatory effects of IFN- $\gamma$ on bone resorption in vivo, we made use of a conditional transgenic mouse that overexpresses a dominant-negative form of TGF- $\beta$ type II receptor (CD $4 d n T G F \beta I I R$ mouse) exclusively in T cells. TGF- $\beta$ signaling in T cells markedly represses $\mathrm{T}$ cell activation. In the absence of the repressive effect of TGF- $\beta$, the T cells of this transgenic secrete increased amounts 

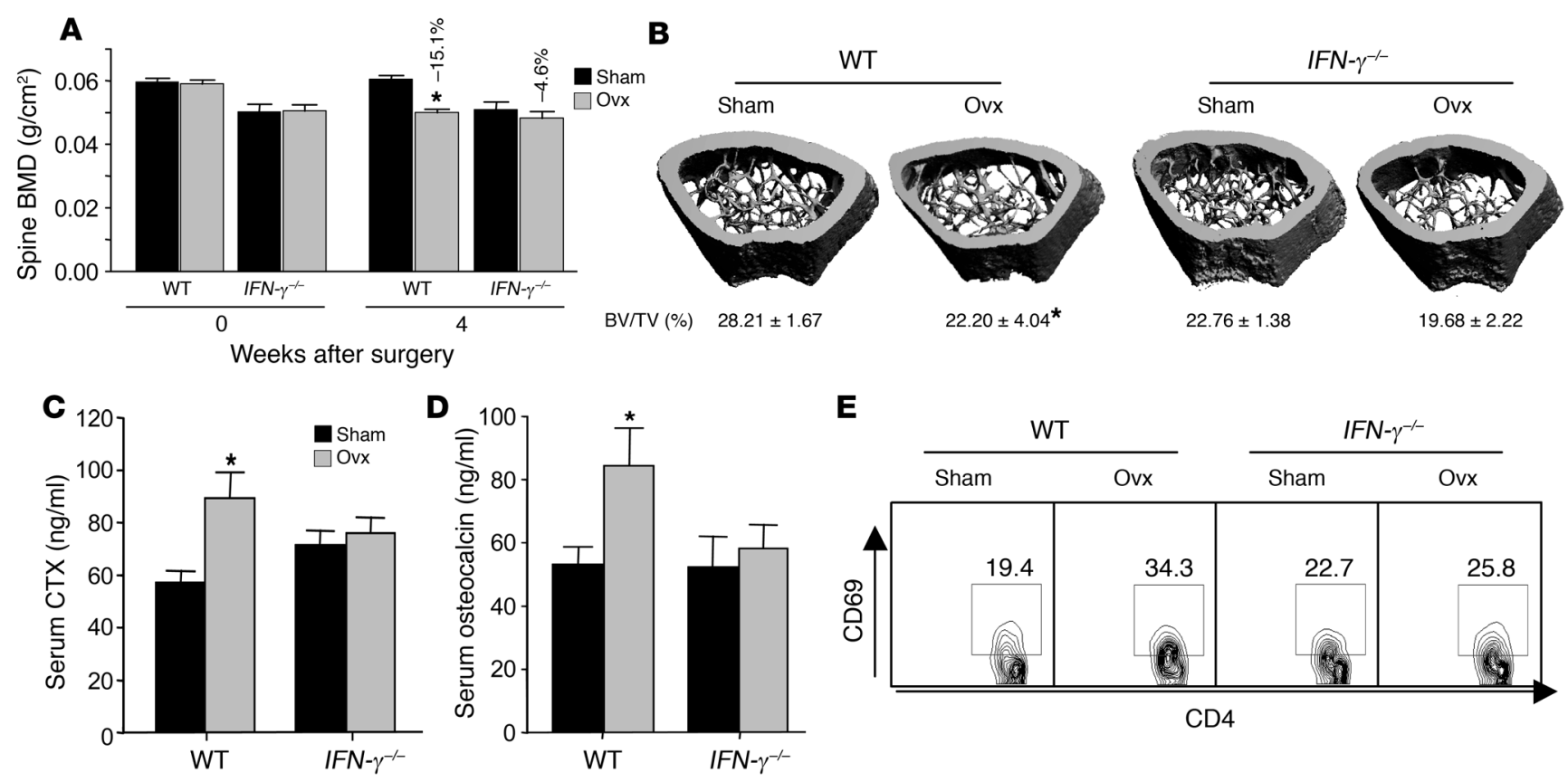

$\mathbf{E}$

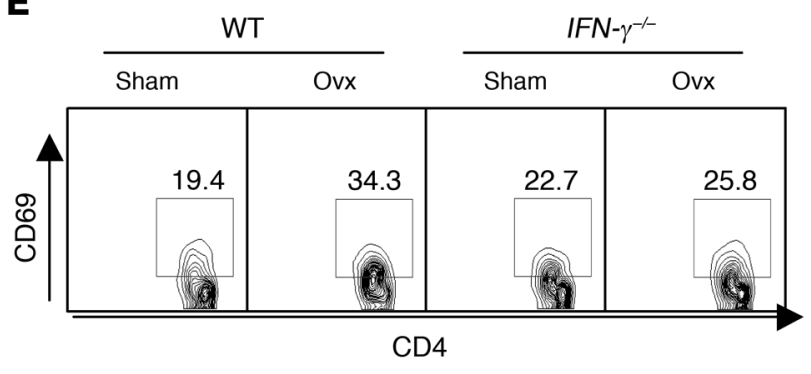

Figure 3

Effects of ovx in WT and IFN- $\gamma^{-1-}$ mice. Sixteen-week-old WT or IFN- $\gamma^{-1-}$ mice were subjected to sham operation or ovx, and BMD (A); BV/TV (by $\mu \mathrm{CT}$ analysis) (B); serum CTX (C) and serum osteocalcin levels (D); and T cell activation (by cytometric detection) (E) were examined 4 weeks after surgery. The percentages in $\mathbf{A}$ represent the change compared with baseline. All data are expressed as mean $\pm \mathrm{SD}$. ${ }^{*} P<0.05$ compared with WT sham controls.

of IFN- $\gamma$, RANKL, and TNF- $\alpha$ (37). IFN- $\gamma$ further stimulates T cell activation and cytokine secretion by promoting antigen presentation. As a result, $C D 4 d n T G F \beta I I R$ mice have a lower bone density and increased bone turnover compared with WT controls (37). In order to assess the role of IFN- $\gamma$ in the impaired bone modeling induced by the silencing of TGF- $\beta$ signaling in T cells, CD4dnTGF $\beta I I R$ mice were crossed with $I F N-\gamma^{-/-}$mice to generate mice (CD4dnTGF $3 I I R$ / $\left.I F N-\gamma^{-/}\right)$with $\mathrm{T}$ cells lacking both IFN- $\gamma$ production and TGF- $\beta$ signaling. Spine BMD was measured in WT, CD4dnTGF $\beta I I R$, $C D 4 d n T G F \beta I I R / I F N-\gamma^{-/-}$, and $I F N-\gamma^{-/-}$mice at 8,12 , and 16 weeks of age (Figure 5A). At the latter time point, WT mice achieve their peak BMD, and bone remodeling ensues (38-41).

All groups of genetic mutants were found to have progressively lower BMD values relative to WT mice, consistent with a modeling defect. However, silencing of IFN- $\gamma$ production decreased significantly the modeling defect caused by the lack of TGF- $\beta$ signaling in T cells, as shown by the finding of higher BMD values in CD4dnTGF $3 I I R /$ $I F N-\gamma^{-/-}$mice as compared with CD $4 d n T G F \beta I I R$ mice.

These findings were confirmed by $\mu \mathrm{CT}$ analysis of trabecular bone in the epiphyses of distal femurs harvested at 16 weeks of age. Specifically, CD4dnTGF $3 I I R / I F N-\gamma^{-/-}$mice had BV/TV values lower than those in WT controls but higher than those in CD4dnTGF $\beta I I R$ mice. Thus, the decrease in BV/TV induced by the lack of TGF- $\beta$ signaling in T cells was partly rescued by the silencing of IFN- $\gamma$ production (Figure 5B). Similarly, the increases in CTX levels (Figure 5C) and in the number of CD69+ $\mathrm{T}$ cells (Figure 5D) characteristic of CD4dnTGF $\beta I I R$ mice were less severe in CD4dnTGF $\beta I I R / I F N-\gamma^{-/-}$mice, while serum osteocalcin was not affected by the silencing of TGF- $\beta$ signaling and/or IFN- $\gamma$ production (Figure 5E). Antigen presentation by macrophages (Figure 6A) and the macrophage mRNA levels of class II transactivator (CIITA) (Figure 6B), a key inducer of MHC class II gene expression, were higher in CD4dnTGF $\beta I I R$ mice than in WT and CD4dnTGF $3 I I R /$ $I F N-\gamma^{-/-}$mice. This is consistent with a high production of IFN- $\gamma$ by activated $\mathrm{T}$ cells in $C D 4 d n T G F \beta I I R$ mice.

As activated $T$ cells induce bone destruction through enhanced production of osteoclastogenic cytokines by $\mathrm{T}$ cells, we measured TNF- $\alpha$ and RANKL production in T cell CM from all groups of mice following a 72-hour culture in the presence of PMA and ionomycin. Compared with that in T cells from WT mice, TNF- $\alpha$ and RANKL production was 4- to 6-fold higher in CD4dnTGF $\beta I I R$ $\mathrm{T}$ cells and 2- to 4-fold higher in CD4dnTGF $3 I I R / I F N-\gamma^{-/-} \mathrm{T}$ cells (Figure 6, C and D). Together, these findings confirm that silencing of TGF- $\beta$ signaling in T cells causes bone loss in part by directly promoting the T cell production of TNF- $\alpha$ and RANKL and in part by promoting the secretion of IFN- $\gamma$, which further stimulates $\mathrm{T}$ cell activation through increased antigen presentation.

To quantify the relevance of IFN- $\gamma$ in the bone loss induced by silencing of TGF- $\beta$ signaling in T cells, we adoptively transferred $\mathrm{T}$ cells from WT, CD4dnTGF $\beta I I R$, and CD4dnTGF $\beta I I R / I F N-\gamma^{-/-}$ mice into $\mathrm{T}$ cell-deficient nude mice. The transfer of $\mathrm{T}$ cells from $C D 4 d n T G F B I I R$ mice caused an approximately 2-fold larger decrease in spine BMD (Figure 7A) and femur BV/TV (Figure 7B) and a greater increase in CTX levels (Figure 7C) than the transfer of both WT $\mathrm{T}$ cells and CD4dnTGF $\beta I I R / I F N-\gamma^{-1-} \mathrm{T}$ cells. In contrast, transfer of T cells from CD4dnTGFBIIR or CD4dnTGF $3 I I R / I F N-\gamma^{-/}$mice to nude mice failed to change serum levels of osteocalcin when compared with the transfer of $\mathrm{T}$ cells from WT mice (Figure 7D). Thus, the IFN- $\gamma$-mediated pathway accounted for approximately $50 \%$ of the bone loss induced by the silencing of TGF- $\beta$ signaling in T cells. 

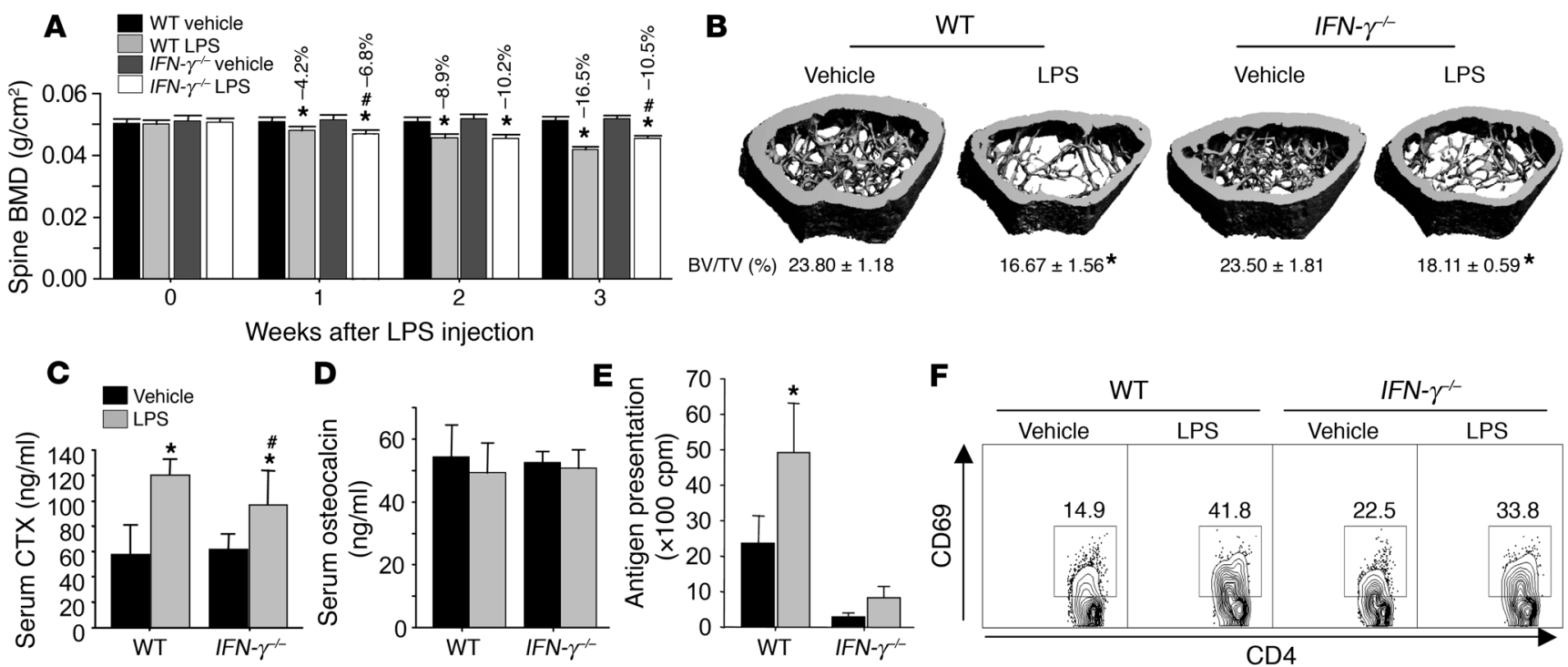

\section{Figure 4}

Effects of LPS treatment for 3 weeks in WT and IFN- $\gamma^{-1-}$ mice. LPS (25 mg/kg body weight) was injected once a week in 16-week-old mice. All mice were sacrificed at the end of the LPS treatment and bone, BM, and serum samples analyzed. (A) In vivo BMD measurements by DXA were obtained at baseline and weekly thereafter. (B) Analysis of BV/TV by $\mu$ CT. (C) Serum CTX. (D) Serum osteocalcin. (E) Antigen presentation assay. (F) Measurement of CD4 and CD69 expression by flow cytometric analysis. The percentages in A represent the change compared with baseline. All data are expressed as mean \pm SD. ${ }^{*} P<0.05$ compared with vehicle-treated controls. $\# P<0.05$ compared with LPS-treated WT mice.

\section{Discussion}

IFN- $\gamma$ has complex and apparently contradictory actions on osteoclastogenesis and bone resorption, depending on the system and model employed. In this study, we have examined the balance between the direct anti-osteoclastogenic effects of IFN- $\gamma$ and the indirect proresorptive activities of IFN- $\gamma$ in vivo, using 3 different murine models of pathological bone turnover. Our data demonstrates that in experimental models of postmenopausal osteoporosis, bacteria-induced infection, and inflammation, the net balance between the direct antiresorptive activities of IFN- $\gamma$ and its proresorptive effects is biased in favor of osteoclastogenesis and bone resorption. Our data confirms previous studies demonstrating direct anti-osteoclastogenic activities of IFN- $\gamma$ on the process of osteoclast differentiation in vitro. However, we further demonstrate that in vivo, the net effect of IFN- $\gamma$ is to potently stimulate osteoclastogenesis, a consequence of its capacity to upregulate antigen presentation. This process leads to $\mathrm{T}$ cell activation and proliferation, with a consequent upregulation in the production of the key osteoclastogenic cytokines RANKL and TNF- $\alpha$. In vivo, this indirect proosteoclastogenic activity overcomes the direct suppressive activities of IFN- $\gamma$ on osteoclast precursors, leading to a net bone loss.

It is reported that preexposure of osteoclast precursors to RANKL renders them resistant to the inhibitory effect of IFN- $\gamma$ (9). It is thus likely that in vivo, as RANKL concentrations begin to rise - a consequence of IFN- $\gamma$-driven antigen-dependent $\mathrm{T}$ cell activation - the direct anti-osteoclastogenic activity of IFN- $\gamma$ may become progressively muted. Furthermore, as the dominant source of IFN- $\gamma$ is activated T cells, a potent amplificatory loop is likely established that further drives up and sustains antigen presentation and $\mathrm{T}$ cell activation, thus perpetuating an inflammatory and proresorptive environment.

Our experimental disease models highlight the central role of $\mathrm{T}$ cells in the process of IFN- $\gamma$-driven bone resorption. This is underscored by experiments showing that $\mathrm{T}$ cell-deficient nude mice fail to undergo bone loss following rIFN- $\gamma$ administration. IFN- $\gamma$-induced bone loss was reversed by $\mathrm{T}$ cell reconstitution and is consistent with the fact that IFN- $\gamma$ has been shown to stimulate bone resorption only in humans or experimental models possessing a normal $\mathrm{T}$ cell lineage $(14-16,42)$, while the vast majority of previous studies concluding that IFN- $\gamma$ is a bone-sparing cytokine made use of the nude mouse model and/or T cell-depleted in vitro cultures $(12,13)$. Interestingly, Takayanagi et al. reported that IFN- $\gamma$ represses bone resorption in a T cell-replete model, but the only in vivo data presented in the report were derived from calvariae from prepubertal mice (7). Thus, the significance of these observations in mature bone and long bones remains unknown. Our studies failed to identify a significant repressive effect of IFN- $\gamma$ on bone resorption in nude mice, an unexpected finding in view of the absence of the $\mathrm{T}$ cell-driven proresorptive activity. However, it is conceivable that a longer IFN- $\gamma$ treatment period may have allowed for the direct inhibitory effect of IFN- $\gamma$ to predominate. Alternatively, it is possible that a relatively higher concentration of IFN- $\gamma$ might be required to decrease bone resorption in this strain. This hypothesis is suggested by the presence of an increased number of osteoclasts and a higher rate of bone resorption in nude mice than WT controls $(43,44)$.

Of additional interest was the finding of a lower baseline bone density in $I F N-\gamma^{-/-}$mice than in WT mice. This was not unexpected, since the indirect proresorptive activity of IFN- $\gamma$ overrides its direct anti-osteoclastogenic activity only in conditions of increased $\mathrm{T}$ cell activation. In contrast, in unstimulated conditions, IFN- $\gamma$ exerts only its direct anti-osteoclastogenic activity. As a result, bone density is lower in adult IFN- $\gamma^{-/-}$than congenic WT mice, because of the long-term impact of the absence of the direct anti-resorptive activity of IFN- $\gamma$.

Combined measurements of cortical and trabecular bone by DXA revealed that ovx caused a significant bone loss in WT but not 

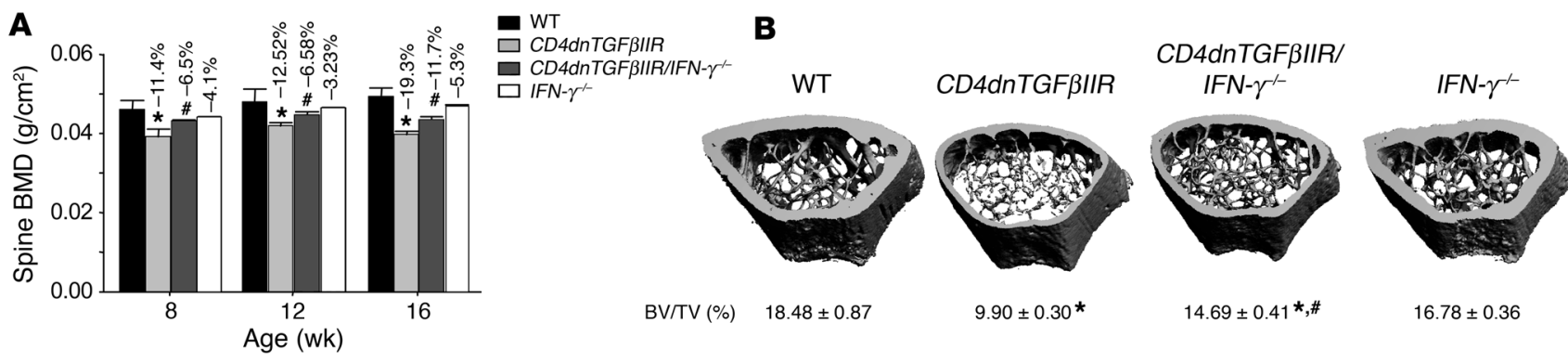

BV/TV (\%) $\quad 18.48 \pm 0.87$

$9.90 \pm 0.30$ *

$14.69 \pm 0.41 *, \#$

$16.78 \pm 0.36$
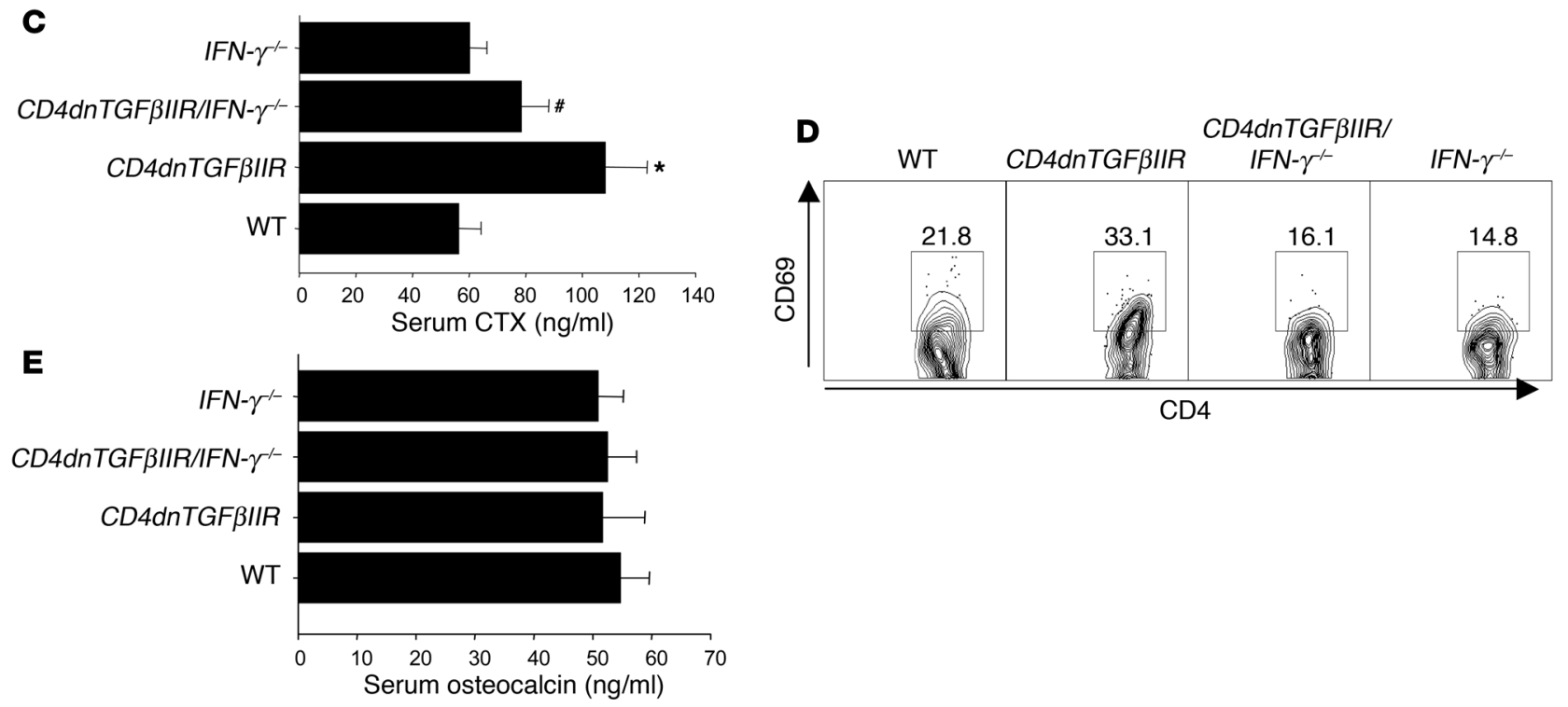

Figure 5

Silencing of IFN- $\gamma$ production reduces the increase in bone loss and T cell activation induced by the disruption of TGF- $\beta$ signaling in T cells. In vivo BMD measurements by DXA (A), $\mu$ CT analysis of trabecular bone (B), serum CTX (C) and T cell activation assays (D), and serum osteocalcin measurements (E) were carried out in 16-week-old intact WT, CD4dnTGF $\beta / I R, C D 4 d n T G F \beta / I R / I F N-\gamma^{-1}$, and IFN- $\gamma^{-1-}$ mice. The percentages in A represent the change compared with age-matched WT controls. All data are expressed as mean $\pm \mathrm{SD}$. ${ }^{*} P<0.05$ compared with age-matched WT control mice. ${ }^{P} P<0.05$ compared with $C D 4 d n T G F \beta / I R$ mice.

in $I F N-\gamma^{-/-}$mice. These data are consistent with a previous report from our laboratory showing that $I F N-\gamma R^{-1-}$ mice fail to undergo bone loss following ovx (2). Selective measurements of trabecular bone by $\mu \mathrm{CT}$ showed that silencing of IFN- $\gamma$ affords significant protection against the bone loss induced by ovx, although it did not completely prevent bone loss. These findings may suggest a more relevant role of IFN- $\gamma$ in the loss of cortical bone than in the loss of trabecular bone following ovx. Although the finding that silencing of IFN- $\gamma$ protects, in part, against ovx-induced bone loss does not establish a cause-effect relationship, the data strongly suggest that under in vivo conditions of estrogen deficiency, IFN- $\gamma$ possesses pro-osteoclastogenic and bone-wasting effects that prevail over the direct anti-osteoclastogenic activity that is dominant in vitro. The results of the current investigation are consistent with an earlier report demonstrating that ovx expands the size of the $\mathrm{T}$ cell pool via an IL-7-dependent increase in both the peripheral expansion of $\mathrm{T}$ cells and the output of recently produced naive $\mathrm{T}$ cells from the thymus (45). Attesting to the relevance of these phenomena, ovx-induced bone loss is decreased by thymectomy and completely prevented by IL-7 neutralization (45). IL-7 stimulates the production of IFN- $\gamma$, while TGF- $\beta$, a cytokine directly regulated by estrogen, blocks the production of both IL-7 and IFN- $\gamma$. It is thus likely that the increase in the levels of both IL-7 and
IFN- $\gamma$ characteristic of ovx mice results from the blunted production of TGF- $\beta$ induced by ovx. Because IL-7 and IFN- $\gamma$ are under reciprocal control, silencing of either factor affords significant protection against ovx-induced bone loss. The finding that IFN- $\gamma$ is implicated in the mechanism of ovx-induced bone loss provides further support for our hypothesis that an increased production of osteoclastogenic cytokines by activated $\mathrm{T}$ cells plays a pivotal role in the bone loss that follows estrogen withdrawal (1). Evidence in favor of this hypothesis includes the reported failure of ovx to induce trabecular and cortical bone loss in nude mice $(33,34,37)$. While an independent confirmation was provided by a preliminary report by Watanabe et al. (46), a more recent study by Lee et al. (44) showed that nude mice lose trabecular bone after ovx, although they are protected against the loss of cortical bone. The partially negative outcome of this study is most likely explained by experimental design differences. Our $\mu \mathrm{CT}$ analysis of the effects of ovx in nude mice was conducted in mature, 16-week-old animals (37). In the same investigation, prospective in vivo measurements of BMD were obtained by DXA (37). Lee et al. (44) conducted their $\mu$ CT analysis in 5- to 6-week-old mice, an age when in most strains ovx blunts trabecular bone formation (38-41). Accordingly, they found ovx to decrease osteoblast surface per bone surface (ObS/BS) (a static histomorphometric index of bone formation) in nude 

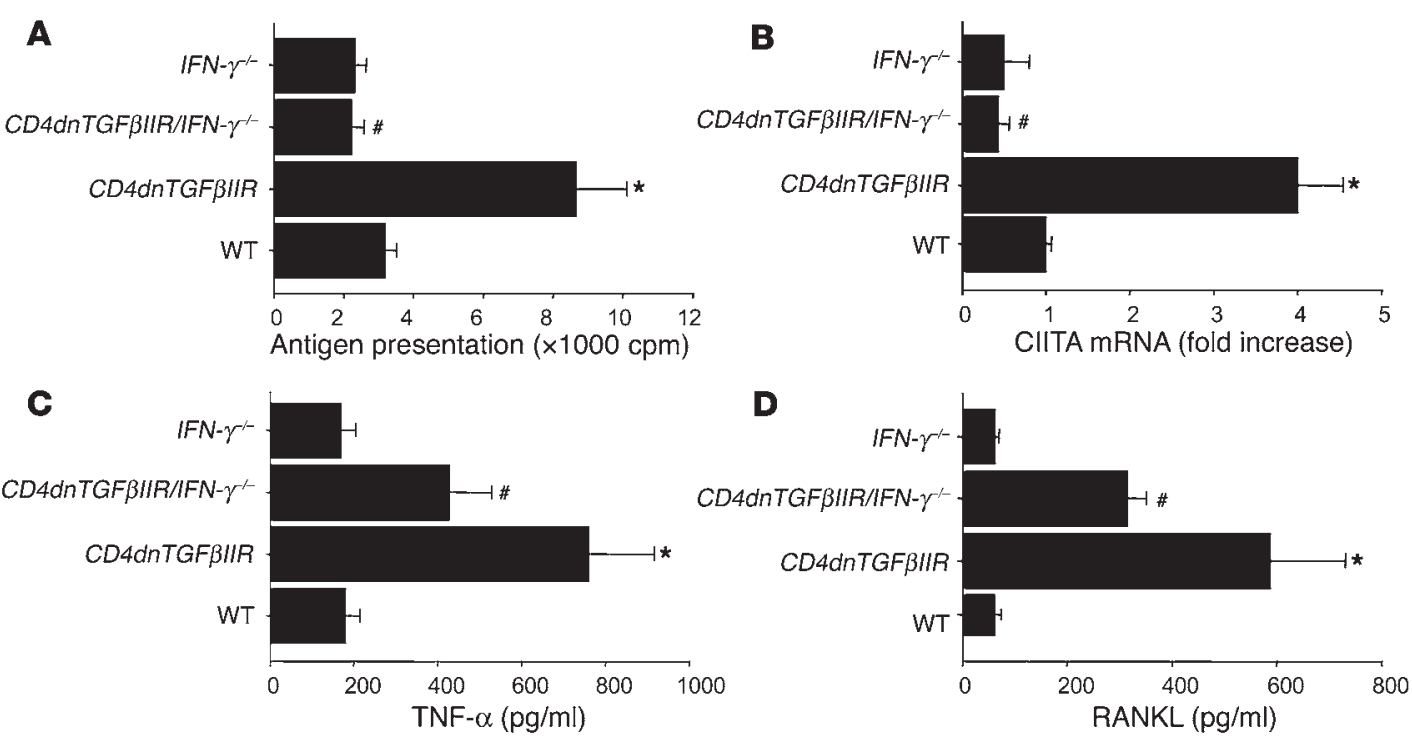

\section{Figure 6}

Silencing IFN- $\gamma$ production reduces the increase in antigen presentation and T cell cytokine production induced by the disruption of TGF- $\beta$ signaling in bone T cells. BMMs and spleen T cells were purified from spleens of 16-week-old WT, CD4dnTGF $\beta / I R, C D 4 d n T G F \beta / I R / I F N$ - $\gamma^{-1-}$, and IFN- $\gamma^{-1-}$ mice and pooled by group. Antigen presentation (A) and CIITA expression (B) were assayed in BMMs. Cytokine levels (C and D) were measured by ELISA in CM of T cells cultured for 3 days in the presence of $100 \mathrm{ng} / \mathrm{ml} \mathrm{PMA}$ and $100 \mathrm{ng} / \mathrm{ml}$ ionomycin. All data are expressed as mean \pm SD. ${ }^{*} P<0.01$ compared with WT mice; ${ }^{\#} P<0.05$ compared with $C D 4 d n T G F \beta / I R$ mice.

mice and to increase it in WT controls (44). They also found ovx not to increase osteoclast surface per bone surface (OcS/BS) and the number of osteoclasts per unit of bone perimeter (NOcBpm) ( 2 sensitive indices of bone resorption) in both WT and nude mice (44). These findings raise the possibility that the main effect of ovx in very young $\mathrm{T}$ cell-deficient mice is that of blunting bone formation rather than increasing bone resorption, leading ovx to cause an arrest in skeletal growth, rather than bone loss. Prospective in vivo measurements of bone density and analysis of dynamic histomorphometric indices of bone formation in mature mice will be required to reconcile our studies with those of Lee et al.

The mechanisms of LPS-induced bone loss are poorly understood. Our data demonstrate that LPS treatment led to a significant increase in antigen presentation and $\mathrm{T}$ cell activation in WT mice, while IFN $\mathrm{\gamma}^{-/-}$mice displayed low basal antigen presentation and failed to undergo a significant upregulation in antigen presentation following LPS administration. T cell activation was also blunted in IFN- $\gamma^{-/-}$mice. Nonetheless, LPS elicited similar trabecular bone loss in $\mathrm{IFN}_{-\gamma^{-/}}$and WT mice, although LPS-induced osteoclastic bone resorption and BMD decrements were modestly, but significantly, reduced in the IFN- $\gamma^{-/-}$mice. These data suggest that the direct and indirect effects of IFN- $\gamma$ on trabecular bone mass cancel each other out, thus resulting in an apparent similar trabecular bone-wasting effects of LPS in IFN- $\gamma^{-1-}$ and WT mice. The data further suggest that LPS mediates bone resorption by both IFN- $\gamma$-dependent and IFN- $\gamma$-independent pathways, although the independent pathway appears to be dominant. This interpretation is consistent with studies reporting that LPS induces osteoclast formation by multiple mechanisms, including direct stimulation of RANKL expression in osteoblasts (47); production of TNF- $\alpha$, IL-1, and IL- 6 by macrophages; and stimulation of osteoclast survival (48). Our data suggest that these proresorptive effects are further amplified by IFN- $\gamma$-mediated pathways.
TGF- $\beta$ is a potent antiinflammatory cytokine that prevents $\mathrm{T}$ cell activation via 2 distinct mechanisms, direct signaling in $T$ cells and inhibition of antigen presentation secondary to blunted T cell production of IFN- $\gamma$ (49). The loss of TGF- $\beta$-mediated repression of $\mathrm{T}$ cell activation results in inflammation, autoimmunity $(35,50)$, and increased $T$ cell production of IFN- $\gamma, T N F$, and RANKL (37). IFN- $\gamma$ further stimulates $T$ cell production of osteoclastogenic cytokines by promoting antigen presentation and antigen-dependent $T$ cell activation. In our model whereby $\mathrm{T}$ cell activation is potentiated through selective silencing of TGF- $\beta$ signaling in T cells, silencing of IFN- $\gamma$ was observed to completely suppress antigen presentation. By contrast, $\mathrm{T}$ cell activation and T cell production of TNF- $\alpha$ and RANKL were only $50 \%$ lower in mice lacking both TGF- $\beta$ signaling and IFN- $\gamma$ production compared with those lacking TGF- $\beta$ signaling only, leading to a $50 \%$ reduction in bone loss. These data suggest that IFN- $\gamma$-driven antigen-dependent $\mathrm{T}$ cell activation is responsible for approximately $50 \%$ of T cell TNF- $\alpha$ and RANKL production in this model. The remaining $50 \%$ of TNF and RANKL production is driven by the blockade of the direct repressive effects of TGF- $\beta$ on $T$ cell activation (50).

In conclusion, our data reveal that IFN- $\gamma$ has complex effects that explain the apparent conflicting reports regarding the effects of this cytokine in bone. In common conditions such as estrogen deficiency, infection, and inflammation, inhibition of IFN- $\gamma$ signaling may represent a novel target for the concomitant prevention of both inflammation and bone loss.

\section{Methods}

Animal protocol. All animal procedures were approved by the Institutional Animal Care and Use Committee of Emory University. Mice were maintained under sterile conditions. Homozygous $(n u / n u)$ athymic nude mice, WT mice, OT-II mice, IFN- $\gamma R^{-/-}$mice, and $I F N-\gamma^{-/-}$mice were on a C57BL/6 
A

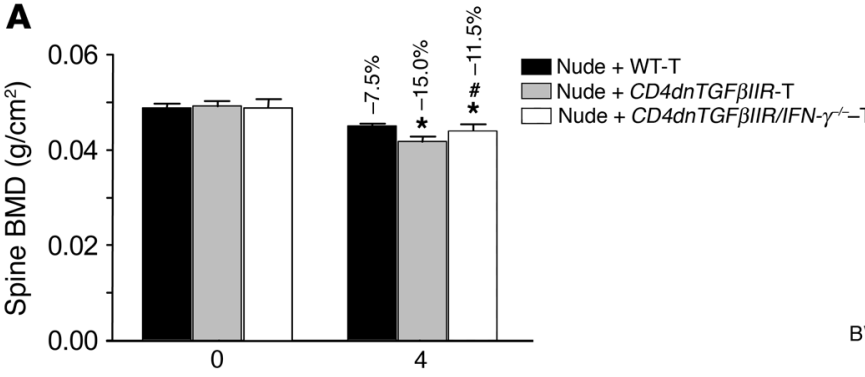

B

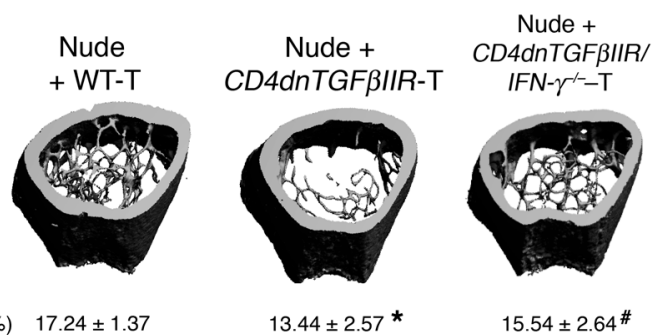

Weeks after $T$ cell reconstitution
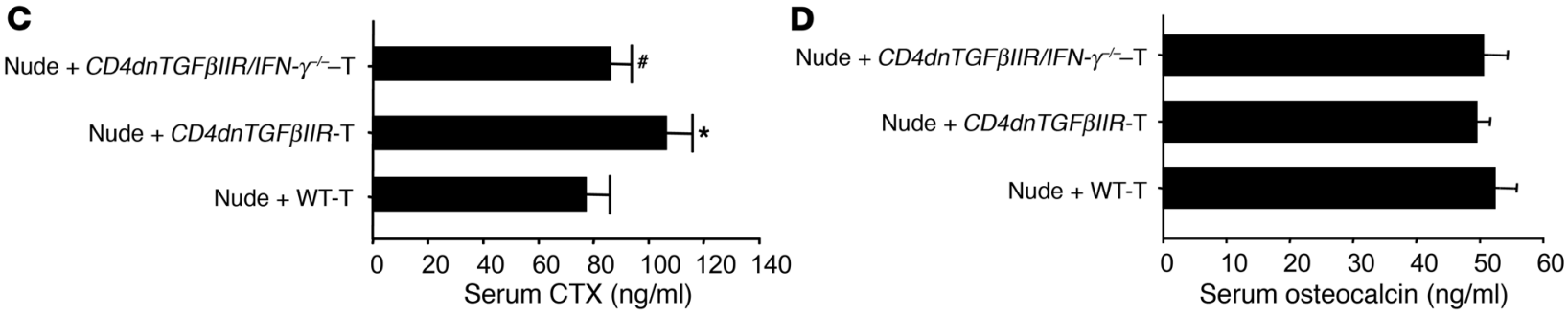

Figure 7

Silencing IFN- $\gamma$ production reduces the increase in bone resorption induced by the disruption of TGF- $\beta$ signaling in T cells. T cells from 16-week-old WT (WT-T), CD4dnTGF $\beta / I R$ (CD4dnTGF $/ I R-T)$, and CD4dnTGF $/ I R / I F N-\gamma^{-1-}$ (CD4dnTGF $\left.\beta / I R / I F N-\gamma^{-1-}-\mathrm{T}\right)$ mice were transferred into 16-week-old T cell-deficient nude mice. Spine BMD measurement (A), $\mu$ CT analysis (B), serum CTX measurement (C), and serum osteocalcin measurement (D) were performed 4 weeks after transplantation. The percentages in A represent the change compared with baseline. All data are expressed as mean $\pm \mathrm{SD}$. ${ }^{*} P<0.05$ compared with nude mice transplanted with T cells from WT mice; ${ }^{*} P<0.05$ compared with nude mice transferred with T cells from CD4dnTGF $\beta$ IIR mice.

background and purchased from The Jackson Laboratory. CD4dnTGF $\beta I I R$ mice on a C57BL/ 6 background were kindly provided by R. Flavell (Yale University School of Medicine, New Haven, Connecticut, USA). The mice $\left(C D 4 d n T G F \beta I I R / I F N-\gamma^{--}\right)$lacking both TGF- $\beta$ signaling in T cells and IFN- $\gamma$ production were established by cross-mating male $C D 4 d n T G F \beta I I R$ mice with female $I F N-\gamma^{-/}$mice. Female mice were either subjected to sham operation or ovx at 16 weeks of age and killed at 20 weeks of age. At sacrifice, 1 tibia was excised for histology and 1 femur for $\mu \mathrm{CT}$ analysis and BM harvested from the remaining bones for ex vivo analysis. Uterine weight was determined at death to verify successful ovx.

$B M M s$ and $T$ cell purification. BMMs and T cells were purified from BM and spleens, respectively, by positive immunoselection using MACS MicroBeads (Miltenyi Biotec) coupled to anti-CD11b Ab and anti-CD90 Ab (Thy1.2) for macrophages and $\mathrm{T}$ cells, respectively, as described previously $(2,37)$. Cell purity was verified to be greater than $90 \%$ by FACS.

$T$ cell adoptive transfer. T cells were purified from the spleens of 16-weekold WT, CD4dnTGF $3 I I R$, and CD4dnTGF $3 I I R / I F N-\gamma^{-/-}$mice and injected $\left(2 \times 10^{7}\right.$ cell per mouse $)$ i.p. into 16 -week-old $\mathrm{T}$ cell-deficient nude recipient mice as previously described $(34,37,43,51)$. Successful $T$ cell engraftment was confirmed by flow cytometry of the spleen and BM of recipient mice 4 weeks after the adoptive transfer.

IFN- $\gamma$ pretreatment and in vitro osteoclastogenesis. BMMs were harvested from 6-week-old WT mice; treated for 72 hours with $10 \mathrm{ng} / \mathrm{ml}$ of rIFN- $\gamma$ in $\alpha$-MEM medium containing 10\% FBS, washed twice with cold PBS (Mediatech Inc.); and cocultured with T cells from OT-II mice in the presence of $0.5 \mathrm{mg} / \mathrm{ml}$ OVA for an additional 72 hours. CM was collected at the end of culture, and the levels of TNF- $\alpha$, RANKL, and IFN- $\gamma$ were measured using ELISA (R\&D Systems). The ability of CM to induce osteoclast formation was examined in BMMs from WT or $I F N-\gamma R^{-/-}$mice in the presence of 10 $\mathrm{ng} / \mathrm{ml}$ RANKL (provided by X. Feng, University of Alabama, Birmingham, Alabama, USA) and $10 \mathrm{ng} / \mathrm{ml}$ M-CSF. Tartrate-resistant acid phosphatase
(TRAP) staining was performed 7 days after culture, and $\mathrm{TRAP}^{+}$cells with more than 3 nuclei were scored as osteoclasts $(52,53)$.

In a separate experiment, BMMs were harvested from sham-operated or ovx WT mice and cultured for 72 hours with T cells from OT-II mice in the presence of $0.5 \mathrm{mg} / \mathrm{ml}$ OVA. CM was collected and used to induce osteoclastogenesis in WT BMMs in the presence of $10 \mathrm{ng} / \mathrm{ml} \mathrm{RANKL}$ and $10 \mathrm{ng} / \mathrm{ml} \mathrm{M-CSF}$ with or without $10 \mu \mathrm{g} / \mathrm{ml}$ IFN- $\gamma \mathrm{Ab}$.

Measurement of preosteoclast proliferation and survival. The proliferation of osteoclast precursors at 3 days was quantitated by thymidine incorporation. $\mathrm{TRAP}^{+}$mononucleated preosteoclasts were pulsed with $\left[{ }^{3} \mathrm{H}\right]$ thymidine $(0.5 \mu \mathrm{Ci} /$ well), for 18 hours of culture. Cells were harvested by using a Cell Harvester (Skatron) and thymidine incorporation determined on a Packard Tri-Carb 4640 Liquid Scintillation Counter (United Technologies). The rate of apoptosis of maturing osteoclasts was determined by measuring intracellular caspase-3 activity, a marker of apoptosis, by the CaspACE Assay System (Promega).

Systemic administration of $r I F N-\gamma$. To investigate the effects of IFN- $\gamma$ on bone turnover in healthy mice and the role of T cells, 16-week-old WT mice, nude mice, and nude mice reconstituted with WT T cells were injected i.p. twice a week for 3 weeks with $\mathrm{rIFN}-\gamma\left(1 \times 10^{6} \mathrm{IU} / \mathrm{kg}\right)$, as previously described (12).

Systemic administration of LPS in vivo. To investigate the contribution of IFN- $\gamma$ to LPS-induced bone resorption in vivo, 10-week-old WT and IFN- $\gamma^{-/-}$ mice were injected subcutaneously with LPS (Sigma-Aldrich) $(25 \mathrm{mg} / \mathrm{kg}$, once a week for 3 weeks), as described previously (7).

Real-time RT-PCR. CIITA, TNF, RANKL, and IFN- $\gamma$ mRNA were quantitated by real-time PCR using a GeneAmp 7000 system (Applied Biosystems) as previously described $(2,37)$. All primers for real-time PCR were designed using Primer Express Software version 2.0 (PE Biosystems). The primers used for CIITA were 5'-CCTATGCCAACATTGCGG A-3' (forward) and 5'-GCTGGGTATCCTGGAACACG-3' (reverse); for TNF, 5'-AACTCCAGGCGGTGCCTAT-3' (forward) and 5'-TGCCACAAGCAGGAATGAGA-3' 
(reverse); for RANKL, 5'-CACAGCGCTTCTCAGGAGCT-3' (forward) and $5^{\prime}$-CATCCAACCATGAGCCTTCC-3' (reverse); for IFN- $\gamma, 5^{\prime}$-CACTGCATCTTGGCTTTGCA-3' (forward) and 5'-GTAACAGCCAGAAACAGCCATG-3' (reverse). mRNA was normalized against $\beta$-tubulin using the primers 5'-GGAGAGCTGTGATTGCCTGC (forward) and 5'-CCACCCAGTGAGTGGGTCAG-3' (reverse). Amplification reactions were performed in 50- $\mu$ l volume using SYBR Green PCR Master Mix (Applied Biosystems). Dissociation curves revealed a single product in all cases. Fold change in cDNA concentration was calculated using the $2^{-\Delta \Delta C T}$ method $(2,37,54)$ with normalization of input using $\beta$-tubulin.

Determination of BMD. Spine BMD was measured in vivo using a PIXImus2 bone densitometer (GE Medical System, Lunar) as previously described $(2,37)$. The short-term reproducibility of this technique is $1.7 \%$ (55). Data were expressed as percent change from baseline.

$\mu C T$ analysis. $\mu \mathrm{CT}$ analysis was performed as reported previously with modification $(37,56)$. Briefly, after removing soft tissues, femurs were fixed overnight in $10 \%$ neutral buffered formalin, washed twice in PBS, and stored in $70 \%$ ethanol at $4{ }^{\circ} \mathrm{C}$ until analysis. $\mu \mathrm{CT}$ scanning and analysis were performed by a technician blinded to the grouping of animals using a Scanco $\mu C T-40$ (SCANCO Medical). The primary spongiosa $(0.5 \mathrm{~mm}$ from the growth plate and extending $0.8 \mathrm{~mm}$ proximally) and secondary spongiosa ( $0.5 \mathrm{~mm}$ from the growth plate and extending $0.5 \mathrm{~mm}$ distally) within the endosteal borders of distal femurs were selected for trabecular analysis. Bones were scanned at a resolution of $12 \mu \mathrm{m}$; tomographic images were obtained at conditions of $70 \mathrm{KV}$ and $114 \mu \mathrm{A}$ by collecting 500 projections each rotation at 200-ms integration time; and reconstruction of 3D images was performed using standard convolution back-projection algorithms with Shepp and Logan filtering and rendered within a 12.3- $\mathrm{mm}$ field of view at a discrete density of 578,704 voxels $/ \mathrm{mm}^{3}$. BV/TV was calculated by measuring $3 \mathrm{D}$ distances directly in the trabecular network. One high-resolution $(6 \mu \mathrm{m})$ $3 \mathrm{D}$ image was generated for 1 representative sample from each group clustering closest to the average indices in the histomorphometric analysis.

Serum CTXs and osteocalcin measurements. Serum CTX levels, a specific marker of bone resorption, were determined using a mouse-specific ELISA assay according to the manufacturer's protocols (Nordic Bioscience Diagnostics). Serum osteocalcin levels, a specific marker for bone formation, were measured using a Rat-MID Osteocalcin ELISA kit (Nordic Bioscience Diagnostics).

Flow cytometry. Flow cytometry was performed as described previously (45), using whole spleen cells triple-labeled with anti-RANKL-conjugated $\mathrm{PE}$ (BioLegend) or anti-TNF- $\alpha$-conjugated PE, anti-CD4-conjugated APC, and anti-CD8-conjugated peridinin-chlorophyll-protein (PerCP) Abs (BD Biosciences - Pharmingen). Spleen cells were also triple labeled with antiCD69-conjugated FITC, anti-CD4-conjugated APC, and anti-CD8-conjugated PerCP (BD Biosciences - Pharmingen). Nonspecific staining was assessed using FITC-, APC-, PerCP-, or PE-conjugated isotype-matched normal IgG Abs (BD Biosciences - Pharmingen). Cells were analyzed on a FACScan flow cytometer (BD).

Antigen presentation activity assay. Antigen presentation was measured as described previously $(2,37)$. Briefly, T cells from OT-II mice on a C57BL/6 background were purified and cultured for 10 days in RPMI-1640 containing $10 \% \mathrm{FBS}, 40 \mathrm{U} / \mathrm{ml} \mathrm{IL-2} \mathrm{(R \& D} \mathrm{Systems),} \mathrm{and} 0.5 \mathrm{mg} / \mathrm{ml}$ OVA. BMMs $\left(5 \times 10^{4} /\right.$ well $)$ were purified from the BM and $\gamma$-irradiated (20 Gy) and cocultured in a 96-well plate for 72 hours with $\mathrm{T}$ cells at a ratio of 1:10 in RPMI-1640 medium containing $10 \% \mathrm{FBS}$ and $0.5 \mathrm{mg} / \mathrm{ml}$ OVA. T cell proliferation induced by macrophage antigen presentation was quantitated by $\left[{ }^{3} \mathrm{H}\right]$ thymidine $(0.5 \mu \mathrm{Ci} /$ well; Amersham Biosciences) incorporation, added during the last 18 hours of culture. Cells were harvested using a Cell Harvester (Skatron), and thymidine incorporation determined on a Packard Tri-Carb 4640 Liquid Scintillation Counter.

Cytokine assays. T cells were harvested using MACS MicroBeads coupled to anti-CD90 (Thy1.2) Abs, as described previously (2), and cultured for 72 hours in the presence of $100 \mathrm{ng} / \mathrm{ml}$ PMA (Sigma-Aldrich) and $100 \mathrm{ng} / \mathrm{ml}$ ionomycin (Sigma-Aldrich). The levels of TNF- $\alpha$, IFN- $\gamma$, and RANKL in the culture media were determined by ELISA (R\&D Systems).

Statistics. All cross-sectional data were analyzed by ANOVA, as well as Kruskal-Wallis test for data not normally distributed. Prospective data were analyzed by ANOVA for repeated measures. Multiple comparisons tests were performed by Fisher's protected least-significant-difference test and Tukey's honestly significant difference tests. Simple comparisons were made using unpaired 2-tailed Student's $t$ test. $P$ values less than or equal to 0.05 were considered significant.

\section{Acknowledgments}

This study was supported in part by grants from the NIH (DK55746, AR 49659, and AG 28278). M.N. Weitzmann was supported in part by NIH grants DK67389 and U54CA119338, the National Osteoporosis Foundation, and the Emory University Research Committee. F. Grassi was supported by a Marie-Curie fellowship from the European Commission (no. 09097).

Received for publication August 15, 2006, and accepted in revised form October 31, 2006.

Address correspondence to: Roberto Pacifici, Division of Endocrinology, Metabolism and Lipids, Emory University School of Medicine, 1639 Pierce Drive, Room 1309, Atlanta, Georgia 30322, USA. Phone: (404) 712-8420; Fax: (404) 727-1300; E-mail: roberto.pacifici@emory.edu.
1. Weitzmann, M.N., and Pacifici, R. 2006. Estrogen deficiency and bone loss: an inflammatory tale. J. Clin. Invest. 116:1186-1194. doi:10.1172/ JCI28550.

2. Cenci, S., et al. 2003. Estrogen deficiency induces bone loss by increasing $\mathrm{T}$ cell proliferation and lifespan through IFN-gamma-induced class II transactivator. Proc. Natl. Acad. Sci. U. S. A. 100:10405-10410.

3. Taubman, M.A., and Kawai, T. 2001. Involvement of T-lymphocytes in periodontal disease and in direct and indirect induction of bone resorption. Crit. Rev. Oral Biol. Med. 12:125-135.

4. Taubman, M.A., Valverde, P., Han, X., and Kawai, T. 2005. Immune response: the key to bone resorption in periodontal disease. J. Periodontol. 76:2033-2041.

5. van Roon, J.A., Glaudemans, K.A., Bijlsma, J.W., and Lafeber, F.P. 2003. Interleukin 7 stimulates tumour necrosis factor alpha and Th1 cytokine production in joints of patients with rheumatoid arthritis. Ann. Rheum. Dis. 62:113-119.
6. Fox, S.W., and Chambers, T.J. 2000. Interferongamma directly inhibits TRANCE-induced osteoclastogenesis. Biochem. Biophys. Res. Commun. 276:868-872

7. Takayanagi, H., et al. 2000. T-cell-mediated regulation of osteoclastogenesis by signalling crosstalk between RANKL and IFN-gamma. Nature. 408:600-605.

8. Madyastha, P.R., Yang, S., Ries, W.L., and Key, L.L., Jr. 2000. IFN-gamma enhances osteoclast generation in cultures of peripheral blood from osteopetrotic patients and normalizes superoxide production. J. Interferon Cytokine Res. 20:645-652.

9. Huang, W., O’Keefe, R.J., and Schwarz, E.M. 2003. Exposure to receptor-activator of NFkappaB ligand renders pre-osteoclasts resistant to IFN-gamma by inducing terminal differentiation. Arthritis Res. Ther. 5:R49-R59.

10. Kotake, S., et al. 2005. IFN-gamma-producing human $\mathrm{T}$ cells directly induce osteoclastogen- esis from human monocytes via the expression of RANKL. Eur. J. Immunol. 35:3353-3363.

11. Vermeire, K., et al. 1997. Accelerated collageninduced arthritis in IFN-gamma receptor-deficient mice. J. Immunol. 158:5507-5513.

12. Sato, K., et al. 1992. Prolonged decrease of serum calcium concentration by murine gamma-interferon in hypercalcemic, human tumor (EC-GI)-bearing nude mice. Cancer Res. 52:444-449.

13. Tohkin, M., Kakudo, S., Kasai, H., and Arita, H. 1994. Comparative study of inhibitory effects by murine interferon gamma and a new bisphosphonate (alendronate) in hypercalcemic, nude mice bearing human tumor (LJC-1-JCK). Cancer Immunol. Immunother. 39:155-160.

14. Key, L.L., Jr. et al. 1995. Long-term treatment of osteopetrosis with recombinant human interferon gamma. N. Engl. J. Med. 332:1594-1599.

15. Rodriguiz, R.M., Key, L.L., Jr. and Ries, W.L. 1993. Combination macrophage-colony stimulating fac- 
tor and interferon-gamma administration ameliorates the osteopetrotic condition in microphthalmic (mi/mi) mice. Pediatr. Res. 33:384-389.

16. Mann, G.N., et al. 1994. Interferon-gamma causes loss of bone volume in vivo and fails to ameliorate cyclosporin A-induced osteopenia. Endocrinology. 135:1077-1083.

17. Goodman, G.R., et al. 1999. Interferon-alpha, unlike interferon-gamma, does not cause bone loss in the rat. Bone. 25:459-463.

18. Baker, P.J., et al. 1999. CD4(+) T cells and the proinflammatory cytokines gamma interferon and interleukin- 6 contribute to alveolar bone loss in mice. Infect. Immun. 67:2804-2809.

19. Arnoldi, J., Gerdes, J., and Flad, H.D. 1990. Immunohistologic assessment of cytokine production of infiltrating cells in various forms of leprosy. Am. J. Pathol. 137:749-753.

20. Firestein, G.S., Alvaro-Gracia, J.M., Maki, R., and Alvaro-Gracia, J.M. 1990. Quantitative analysis of cytokine gene expression in rheumatoid arthritis. J. Immunol. 144:3347-3353.

21. Moriyama, H., Ukai, T., and Hara, Y. 2002. Interferon-gamma production changes in parallel with bacterial lipopolysaccharide induced bone resorption in mice: an immunohistometrical study. Calcif. Tissue Int. 71:53-58.

22. Teng, Y.T., Mahamed, D., and Singh, B. 2005 Gamma interferon positively modulates Actinobacillus actinomycetemcomitans-specific RANKL+ CD4+ Th-cell-mediated alveolar bone destruction in vivo. Infect. Immun. 73:3453-3461.

23. Cannon, G.W., et al. 1989. Double-blind trial of recombinant gamma-interferon versus placebo in the treatment of rheumatoid arthritis. Arthritis Rheum. 32:964-973.

24. Veys, E.M., Menkes, C.J., and Emery, P. 1997. A randomized, double-blind study comparing twenty-four-week treatment with recombinant interferon-gamma versus placebo in the treatment of rheumatoid arthritis. Arthritis Rheum. 40:62-68

25. Takayanagi, H., Kim, S., and Taniguchi, T. 2002. Signaling crosstalk between RANKL and interferons in osteoclast differentiation. Arthritis Res. 4(Suppl. 3):S227-S232.

26. Pang, M., Martinez, A.F., Jacobs, J., Balkan, W., and Troen, B.R. 2005. RANK ligand and interferon gamma differentially regulate cathepsin gene expression in pre-osteoclastic cells. Biochem. Biophys. Res. Commun. 328:756-763.

27. Kamolmatyakul, S., Chen, W., and Li, Y.P. 2001. Interferon-gamma down-regulates gene expression of cathepsin $\mathrm{K}$ in osteoclasts and inhibits osteoclast formation. J. Dent. Res. 80:351-355.

28. Yang, S., Madyastha, P., Ries, W., and Key, L.L. 2002. Characterization of interferon gamma recep- tors on osteoclasts: effect of interferon gamma on osteoclastic superoxide generation. J. Cell. Biochem. 84:645-654.

29. van't Hof, R.J., and Ralston, S.H. 1997. Cytokineinduced nitric oxide inhibits bone resorption by inducing apoptosis of osteoclast progenitors and suppressing osteoclast activity. J. Bone Miner. Res. 12:1797-1804.

30. Chen, H., et al. 2006. Positive regulatory domain I-binding factor 1 mediates repression of the MHC class II transactivator (CIITA) type IV promoter. Mol. Immunol. 44:1461-1470.

31. Mortara, L., et al. 2006. CIITA-induced MHC class II expression in mammary adenocarcinoma leads to a Th1 polarization of the tumor microenvironment, tumor rejection, and specific antitumor memory. Clin. Cancer Res. 12:3435-3443.

32. Langhorne, J., et al. 2004. Dendritic cells, proinflammatory responses, and antigen presentation in a rodent malaria infection. Immunol. Rev. 201:35-47.

33. Cenci, S., et al. 2000. Estrogen deficiency induces bone loss by enhancing T-cell production of TNF- $\alpha$. J. Clin. Invest. 106:1229-1237.

34. Roggia, C., et al. 2001. Up-regulation of TNF-producing $\mathrm{T}$ cells in the bone marrow: a key mechanism by which estrogen deficiency induces bone loss in vivo. Proc. Natl. Acad. Sci. U. S. A. 98:13960-13965.

35. Gorelik, L., and Flavell, R.A. 2000. Abrogation of TGFbeta signaling in $\mathrm{T}$ cells leads to spontaneous $\mathrm{T}$ cell differentiation and autoimmune disease. Immunity. 12:171-181.

36. Lindberg, M.K., et al. 2006. Liver-derived IGF-I is permissive for ovariectomy-induced trabecular bone loss. Bone. 38:85-92.

37. Gao, Y., et al. 2004. Estrogen prevents bone loss through transforming growth factor beta signaling in T cells. Proc. Natl. Acad. Sci. U. S. A. 101:16618-16623.

38. Klein, R.F., et al. 2001. Phenotypic characterization of mice bred for high and low peak bone mass. J. Bone Miner. Res. 16:63-71.

39. Brodt, M.D., Ellis, C.B., and Silva, M.J. 1999. Growing $\mathrm{C} 57 \mathrm{Bl} / 6$ mice increase whole bone mechanical properties by increasing geometric and material properties. J. Bone Miner. Res. 14:2159-2166.

40. Richman, C., et al. 2001. Postnatal and pubertal skeletal changes contribute predominantly to the differences in peak bone density between $\mathrm{C} 3 \mathrm{H} / \mathrm{HeJ}$ and C57BL/6J mice. J. Bone Miner. Res. 16:386-397.

41. He, J., Rosen, C.J., Adams, D.J., and Kream, B.E. 2006. Postnatal growth and bone mass in mice with IGF-I haploinsufficiency. Bone. 38:826-835.

42. Baker, P., Howe, L., Garneau, J., and Roopenian, D. 2002. T cell knockout mice have diminished alveolar bone loss after oral infection with Porphyromonas gingivalis. FEMS Immunol. Med. Microbiol.
34:45-50.

43. Toraldo, G., Roggia, C., Qian, W.P., Pacifici, R., and Weitzmann, M.N. 2003. IL-7 induces bone loss in vivo by induction of receptor activator of nuclear factor kappa B ligand and tumor necrosis factor alpha from T cells. Proc. Natl. Acad. Sci. U. S. A. 100:125-130.

44. Lee, S.K., et al. 2006. T lymphocyte deficient mice lose trabecular bone mass with ovariectomy. J. Bone Miner. Res. 21:1704-1712.

45. Ryan, M.R., et al. 2005. An IL-7-dependent rebound in thymic $T$ cell output contributes to the bone loss induced by estrogen deficiency. Proc. Natl. Acad. Sci. U. S. A. 102:16735-16740

46. Watanabe, $\mathrm{K}$, et al. 2001. Role of T cells and T to $\mathrm{B}$ signaling through CD40 in the pathogenesis of estrogen deficient osteoporosis [abstract]. J. Bone Miner. Res. 16(Suppl. 1):1139.

47. Kikuchi, T., et al. 2003. Cot/Tpl2 is essential for RANKL induction by lipid A in osteoblasts. J. Dent. Res. 82:546-550.

48. Itoh, K., et al. 2003. Lipopolysaccharide promotes the survival of osteoclasts via Toll-like receptor 4, but cytokine production of osteoclasts in response to lipopolysaccharide is different from that of macrophages. J. Immunol. 170:3688-3695.

49. Gorelik, L., Constant, S., and Flavell, R.A. 2002. Mechanism of transforming growth factor betainduced inhibition of $\mathrm{T}$ helper type 1 differentiation. J. Exp. Med. 195:1499-1505.

50. Gorelik, L., and Flavell, R.A. 2002. Transforming growth factor-beta in T-cell biology. Nat. Rev. Immunol. 2:46-53.

51. Rogers, A., and Eastell, R. 1998. Effects of estrogen therapy of postmenopausal women on cytokines measured in peripheral blood. J. Bone Miner. Res. 13:1577-1586.

52. Komori, T., et al. 1997. Targeted disruption of Cbfa1 results in a complete lack of bone formation owing to maturational arrest of osteoblasts. Cell. 89:755-764.

53. Gao, Y.H., et al. 1998. Potential role of cbfa1, an essential transcriptional factor for osteoblast differentiation, in osteoclastogenesis: regulation of mRNA expression of osteoclast differentiation factor (ODF). Biochem. Biophys. Res. Commun. 252:697-702.

54. Livak, K.J., and Schmittgen, T.D. 2001. Analysis of relative gene expression data using real-time quantitative PCR and the 2(-Delta Delta C(T)) method. Methods. 25:402-408.

55. Cenci, S., Weitzmann, M.N., Gentile, M.A., Aisa, M.C., and Pacifici, R. 2000. M-CSF neutralization and egr-1 deficiency prevent ovariectomy-induced bone loss. J. Clin. Invest. 105:1279-1287.

56. Grassi, F., et al. 2006. Bone re/modeling is more dynamic in the eNOS( $\left(^{-/}\right)$mouse. Endocrinology. 147:4392-4399. 